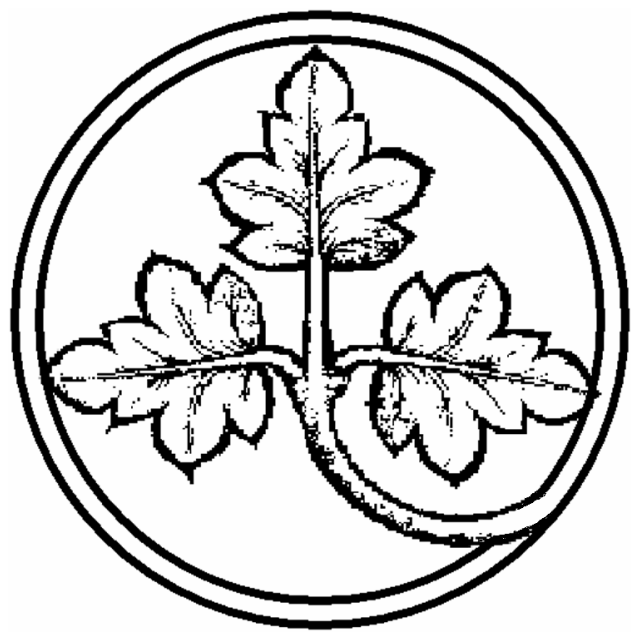

\author{
Preprints of the \\ Max Planck Institute \\ for Research on Collective Goods \\ Bonn \\ 2005/7
}

Monopoly Prices versus Ramsey-Boiteux Prices: Are they "similar", and: Does it matter?

Felix Höffler 


\section{Monopoly Prices versus Ramsey-Boiteux Prices: Are they "similar", and: Does it matter?}

Felix Höffler 


\title{
Monopoly Prices versus Ramsey-Boiteux Prices: Are they "similar", and: Does it matter?
}

\author{
Felix Höffler*
}

January 31, 2004

\begin{abstract}
Ramsey-Boiteux prices and monopoly prices are frequently regarded as being similar. This might suggest that, in particular in network industries with large fixed costs, sometimes monopoly pricing is close to the Ramsey-Boiteux second best and welfare superior to imperfectly regulated prices. This paper tries to specify what is meant by "being similar", and it analyzes the welfare implications that can be drawn from comparing both sets of prices. Interdependence of demand and the impact of competition are discussed. We reinforce the view that monopoly prices are usually not "similar", and even if they are, this implies no positive welfare judgments on monopoly pricing.

Key words: Ramsey Pricing, Regulation, Access Pricing, Termination

JEL-Classification: L33, L50, L94
\end{abstract}

\section{Introduction}

Ramsey prices and monopoly prices are similar, aren't they? It is widely acknowledged that the solution to the Ramsey-Boiteux problem of second best price setting in an environment with increasing returns to scale and the price setting of a monopolist are somewhat similar. Both can be expressed with an "inverse elasticity rule". Goods with low elasticities receive a higher mark-up on their marginal cost than goods with high elasticities. A private firm tries to maximize profits, thus taking money from those who are least likely to abstain from buying the firm's products. A welfare maximizing social planner tries to minimize distortion caused by the departure from marginal cost pricing. She therefore uses high mark-ups only if this will cause little quantity reaction. It is because of the similarity of this reasoning that Ramsey-Boiteux pricing is often called "business oriented" (Laffont and Tirole, 2000, p.63).

This similarity is sometimes used to suggest that withholding from monopoly regulation might be welfare superior to imperfect regulatory interference. A monopolist might set prices a bit higher, but at least this will reflect the "right" structure. Market participants and even academics involved in the political discussion often informally refer to Ramsey arguments.

${ }^{*}$ Max Planck Institute for Research on Collective Goods, Kurt-Schumacher-Str. 10, 53113 Bonn, Germany. Phone: +49(0)228-9141646. hoeffler@coll.mpg.de. I would like to thank Felix Bierbrauer, Christoph Engel and Hendrik Hakenes for helpful comments. Any remaining errors are mine. 
In the UK, mobile operators have strongly relied on Ramsey arguments when trying to justify high prices for mobile call termination. The UK regulator Ofcom reports:

"MNOs [mobile network operators] have made a number of comments in favour of the use of Ramsey prices". For instance, "TMobile claims that the own-price elasticities for the two types of calls [on-net and off-net calls] are very similar and so are relative mark-ups, as required by the Ramsey principle" (Ofcom, 2003, 297298).

For Germany, also in the context of mobile regulation, it has been argued that

"companies already try to come close to the Ramsey pricing structure because this is individually profit maximizing. Ramsey prices are, however, also welfare maximizing for the whole economy."(Kruse, 2003, 11, own translation)

Prieger (1996) reports that in the 90s in the US, the fixed line telecommunication incumbents GTE, Pacific Bell (and other local exchange carriers) have argued to

"lower prices for services also provided by competitors (such as intra-LATA toll calls) and to raise the price of basic phone service of which they are the sole provider. To justify the price shift, the firms typically argue that demand for services that face competition is highly elastic... Underlying such arguments is an appeal to the traditional Ramsey rule..."(Prieger, 1996, 307)

In this short survey we discuss whether such arguments can be justified by economic reasoning. We want to provide some orientation in which case reference to the Ramsey-Boiteux problem makes sense and in which it does not.

In a nutshell, monopoly prices and Ramsey-Boiteux prices are similar only with respect to the logic of how prices are formed. Theoretical arguments show that the structure of both sets of prices can be totally different. Additionally, the introduction of competition drives a wedge even between the reasoning of the Ramsey-Boiteux planner and a profit maximizing firm. While the former is concerned about the market demand elasticities, the latter is only concerned about his own residual demand. Overall, from an economic point of view, reference to Ramsey-Boiteux provides little support for the view that private profit maximization is superior to regulated prices.

The text is organized as follows. Section 2 tries to clarify what could be meant by the statement that those two types of prices are "similar" and why this might matter. Section 3 formally states the classical Ramsey-Boiteux problem. In section 4 we analyze the question of similarity in this standard RamseyBoiteux framework. Section 5 extends the Ramsey-Boiteux framework by (i) introducing competition, (ii) analyzing intermediate good markets, and in particular the issue of "termination" fees. Section 6 concludes. 


\section{Similarity}

Although the view that Ramsey-Boiteux and monopoly prices are similar can be found quite often, usually it is not clear what is meant by similarity. We suggest that similarity can be understood in two ways.

- Logic: The reasoning behind the price setting is similar. However, similar logic can lead to different outcomes.

- Structure: Price systems can have the same structure, in particular if all prices are (a little bit) higher in the one system than in the other or if prices for a product are generally close in either regime. A similar structure also exists if the price ordering is the same, i.e. if a product is more expensive than another one under the one regime it should also be more expensive under the alternative regime.

When does similarity matter? It obviously matters in a normative analysis if it allows us to draw welfare implications, e.g. in the sense that a price system similar to the (optimum) Ramsey-Boiteux price system has positive welfare properties. It also matters in a positive sense, since the analytical framework to which an argumentation refers to and whether references to the Ramsey-Boiteux reasoning are appropriate in that framework should always be clear.

\section{A short recap: The Ramsey-Boiteux versus the Monopolist's Problem}

We want to provide a fairly general framework to discuss both the RamseyBoiteux and the monopolist's problem. Similar formulations can be found in Braeutigam (1989), or Laffont and Tirole (2000).

There are $m, i=1, \ldots, m$, products. The $m$ dimensional vector $q$ represents the quantities of these products. Consumer demand for each product is given by $q_{i}(p)$, where $p$ is the $m$ dimensional vector of prices. Demand might be interdependent, i.e. $\partial q_{i} / \partial p_{j}$ need not be zero. There is a single technology to produce the output, defining a cost function $C(q)$, where $C(q)$ is subadditive for the relevant demand levels. Let CS denote the consumer surplus. Then a social planner would-due to the subadditivity of costs-choose only a single firm to produce the output. Assume that the social planner is restricted to linear pricing. Then she solves the following optimization problem:

$$
\begin{array}{ll} 
& \max _{p_{i}} C S(q)+p q-C(q) \quad \forall i, \\
\text { s.t. } \pi= & p q-C(q)=0
\end{array}
$$

Assume that the restriction is binding (i.e. the Lagrange multiplier $\lambda$ is nonzero) and that the solution is determined by the first order conditions. Then, after some rearrangement, the first order conditions with respect to the relative mark-up on marginal cost $M_{i}$ can be stated as:

$$
M_{i}^{R B}=-\frac{\lambda}{1+\lambda} \frac{1}{\varepsilon_{i i}^{R B}}-\underbrace{\sum_{j \neq i} M_{j}^{R B} \frac{\varepsilon_{j i}^{R B}}{\varepsilon_{i i}^{R B}} \frac{q_{j}^{R B}}{q_{i}^{R B}} \frac{p_{j}^{R B}}{p_{i}^{R B}}}_{\text {correction term }},
$$


where

$$
\begin{aligned}
M_{i} & =\frac{p_{i}-\frac{\partial C}{\partial q_{i}}}{p_{i}} \\
\varepsilon_{j i} & =\frac{\partial q_{j}}{\partial p_{i}} \frac{p_{i}}{q_{j}} .
\end{aligned}
$$

This is the classical "inverse elasticity rule" with interdependent demand. In the case of independent demand, the mark-up in excess of the marginal cost, which is necessary to cover the production cost (say, to cover fixed cost), is proportionate to the inverse of the price elasticity of demand. In case of interdependent demand, this needs to be corrected: the mark-up should be smaller (larger) for complements (substitutes). Otherwise the price for a complement would not account for the distortion imposed on the other complementary products. The correction term must be larger in absolute terms, the more important the complementary good is (the higher the revenue is) and the higher the distortion (i.e. the mark-up) of this product is.

A monopolist, with the same production technology available as the social planner, and facing competition in none of the markets, solves the following problem:

$$
\max _{p_{i}} p q-C(q) \quad \forall i
$$

The first order conditions can be expressed as:

$$
M_{i}^{M}=-\frac{1}{\varepsilon_{i i}^{M}}-\underbrace{\sum_{j \neq i} M_{j}^{M} \frac{\varepsilon_{j i}^{M}}{\varepsilon_{i i}^{M}} \frac{q_{j}^{M}}{q_{i}^{M}} \frac{p_{j}^{M}}{p_{i}^{M}}}_{\text {correction term }} .
$$

The monopolist also uses an "inverse elasticity rule". Where demand is less elastic, the monopolist will be able to extract more rent, as consumers will be less prone to abstain from purchasing the good. When demand is interdependent, the monopolist will account for that similarly to the way a social planner will. He will add a (positive) correction in case of substitutes in order to account for the "externality" among goods. Compare the case where the monopolist either produces only one good $i$ with the case where he also produces the substitute $j$. In the first case, he will set a relatively low price, otherwise revenues and profits would decrease, since consumers would switch to the substitute if prices were too high. If he, however, produces both products, he will account for that effect: he will set a higher price since he will also receive the payments from the consumers switching to the substitute.

\section{Comparing Ramsey-Boiteux and Monopoly Pric- ing in the basic framework}

\subsection{Independent Demand without Competition}

In this most simple case, where the "correction terms" are zero, comparing (1) and (2) shows: 
Observation 1 Both sets of prices are similar in the sense that mark-ups follow the same logic: they are higher for markets where, in equilibrium, the elasticity of demand is lower, i.e.:

$$
M_{i}>M_{j} \text { if and only if } \varepsilon_{i i}<\varepsilon_{j j},
$$

i.e. the mark-ups will be higher for goods with lower price elasticity.

The monopoly prices are not just a linear transformation of the RamseyBoiteux prices, since generally elasticities differ at the monopoly quantity and the Ramsey-Boiteux quantity. It is therefore misleading to think of monopoly prices merely as "Ramsey-Boiteux prices on a higher level". Only for the special case of constant elasticity of demand is this perception correct, and there is a single multiplier (larger than one) which transforms each Ramsey-Boiteux price into the monopoly price.

Observation 2 Only in case of constant elasticities of demand, is the vector of monopoly mark-ups $M^{M}$ just a (scalar) multiple of the Ramsey-Boiteux vector of mark-ups $M^{R B}$ :

$$
M^{M}=(1+\lambda) M^{R B}, \lambda>1 \text {. }
$$

It is trivial but important to note that monopoly prices are higher than Ramsey-Boiteux prices and that they therefore lead to welfare inferior allocations. Nothing can be said in general about the degree to which both allocations deviate from each other in terms of social welfare.

Observation 3 The monopolistic mark-up will be larger than the Ramsey-Boiteux mark-up in each market. Thus, the quantities realized are lower and the social surplus is smaller in the case of a monopoly.

Since it is frequently and informally stated that both sets of prices have the same "structure", it is important to note that this is not true for the order of the prices. The order of prices can be different. Goods which are relatively inexpensive under Ramsey-Boiteux pricing can be expensive under monopoly pricing, and vice versa.

Observation 4 The size of the mark-ups need not be in the same order:

$$
M_{i}^{M}>M_{j}^{M} \nRightarrow M_{i}^{R B}>M_{j}^{R B} .
$$

To see why Observation 4 is true, consider the following kinked linear demand example, depicted in Figure 1. There are two markets with independent demands. Market 2 has a linear demand function. Market 1 has a piecewise linear demand function. Assume marginal costs equal zero. Monopoly prices (which equal the mark-ups) can be derived geometrically as $p_{1}^{M}$ and $p_{2}^{M}, p_{1}^{M}>p_{2}^{M}$. Assume that the social planner has to set prices such that some small amount of fixed cost $F$ is covered. Consider first the case where both prices would be the same, $p_{1}^{R B}=p_{2}^{R B}=\overline{p^{R B}}$ : This would imply $\left|\varepsilon_{1}\right|>\left|\varepsilon_{2}\right|$, which, together with $p_{1}=p_{2}$, cannot be optimal. Thus, the planner has to raise $p_{2}$ relative to $p_{1}$, which also increases $\varepsilon_{2}\left(p_{2}\right),{ }^{1}$ until eventually $\varepsilon_{2}\left(p_{2}\right) p_{2}=\varepsilon_{1}\left(p_{1}\right) p_{1}=-(\lambda / 1+\lambda)$,

\footnotetext{
${ }^{1}$ Note that the elasticity is given by the (negative) ratio of the distances from the point on the demand curve to the intersection of the demand function with the $\mathrm{x}$-axis and the $\mathrm{y}$-axis, respecitvely. The absolute value of the elasticity thus strictly increases in $p$ along the demand function. Since the lower part of the first demand function is parallel to the second demand function, at $\overline{p^{R B}}$ we have $\varepsilon_{1}>\varepsilon_{2}$.
} 
the optimality condition from (1). Thus, the social planner would choose $p_{2}^{R B}>p_{1}^{R B}$, while $p_{2}^{M}<p_{1}^{M}$.

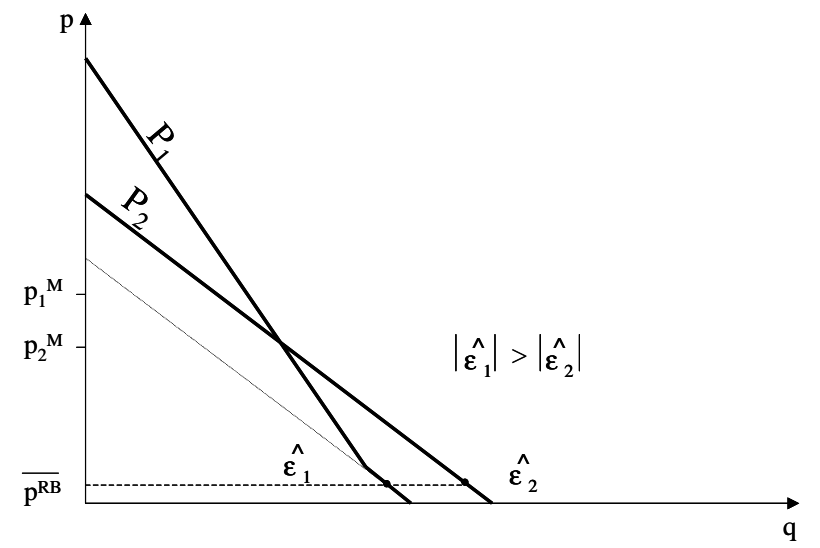

Linear Demand Example

Summary: In the most simple case of the Ramsey-Boiteux analysis, RamseyBoiteux and monopoly prices are similar with respect to the logic of how they are derived. They can, however, lead to totally different price structures. The welfare level is necessarily lower in case of monopoly-and nothing can be said about how much lower.

\subsection{Interdependent Demand without Competition}

With interdependent demand, the "correction terms" do not vanish. They have the same sign, since both the Ramsey-Boiteux planner and the monopolist follow the same reasoning in accounting for the demand interdependencies. Both want to avoid lower demand for complementary products and too high demand in case where the demand can also be satisfied by substitutes. A comparison of (1) and (2) shows that (for downward sloping demand functions) this is generally true, as stated in the next Observation.

Observation 5 The "correction terms" in (1) and (2) have the same sign. The Ramsey-Boiteux planner and a monopolist apply the same logic when correcting for interdependencies of demand among markets.

The size of the correction terms is, however, different. This introduces additional scope for deviations between monopoly pricing and Ramsey-Boiteux pricing.

Clearly, following the same "logic" of orientation at price elasticities does, again, not imply anything about the extent to which the monopolist's solution deviates from the Ramsey-Boiteux solution in terms of social welfare. The only thing that is for sure is that the welfare level under monopoly will be smaller.

Summary: Demand interdependencies introduce an additional influence that can increase the difference between Ramsey-Boiteux and monopoly prices. 


\section{Extensions of the basic Ramsey-Boiteux frame- work}

\subsection{Introducing Competition in one market}

The classical articles (Ramsey (1927), Boiteux (1956)), and in fact many informal references to the "inverse elasticity rule", have in mind a setting in which there is only a single firm. In most applications, however, there will be at least some sort of competition in at least some of the markets. This will influence both sets of prices.

Consider the case discussed so far where there is only a single firm serving all markets. Imagine now that one market $j$ is opened to competition and a competitor enters the market. This highlights a key difference between RamseyBoiteux and Monopoly reasoning. A private firm always focuses on the own residual demand function. Only in the case of monopoly does this coincide with the market demand function and only this coincidence is responsible for the similarities between Ramsey-Boiteux and monopoly pricing.

In market $j$, the "monopolist" will optimize against his residual demand function and no longer against the market demand function (and demand interdependencies will also be considered with respect to the residual demand in market $j$ ). The form of the residual demand function is not generally determined; instead, it hinges upon the assumptions about the strategic interaction between the players and the assumptions about the consumer behavior. Well known examples for assumptions about the strategic interaction are: (i) Stackelberg leadership for the incumbent, which leads to a relatively inelastic residual demand function (Fixed quantity $\overline{q_{j}}$ of the incumbent, the entrant optimizes against a residual demand function of the form $q_{j}^{E}=q_{j}-\overline{q_{j}}$.). (ii) Bertrand competition, which yields perfectly elastic demand function. Examples of assumptions about the consumer behavior are different rationing rules ("proportionate" versus "efficient" rationing).

It might nevertheless be reasonable to assume that for each quantity $q_{j}$ of the former monopolist, the residual demand function is more elastic than the market demand function, since customers can switch to the competitor. By the same reasoning, the absolute value of the cross-price elasticity is likely to be smaller for any given quantity vector of the monopolist if there is competition in market $j$. Consider an increase in price $i$. If products $i$ and $j$ are substitutes, not all consumers' substitution away from $i$ will arrive at the monopolists offering in market $j$, since some consumers might buy good $j$ from the entrant. Vice versa for complements. With these assumptions on the elasticities of the residual demand function, we can state:

Observation 6 Compared to the situation without competition, the mark-up in the competitive market $j$ will decrease, and the mark-ups in the other markets

- remain unchanged in the case of independent demand;

- still have the same sign but become smaller in absolute terms in case of interdependent demand. ${ }^{2}$

${ }^{2}$ The mark-up $M_{j}$ becomes smaller due to the introduction of competition in market $j$. We have assumed also that $\varepsilon_{j i}$ decreases. A monopolist chooses a point on the demand function 


\section{Electricity Prices}

Germany

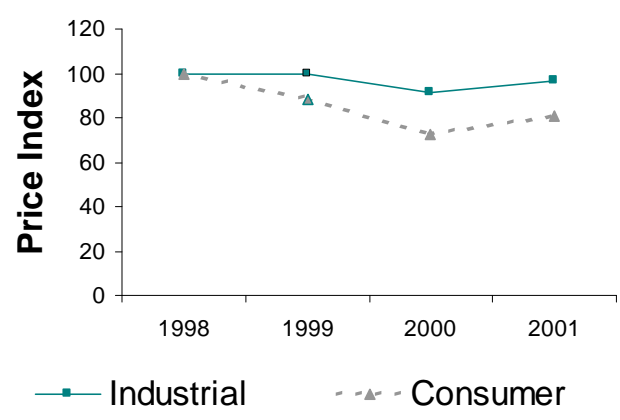

Source: German Ministry of Economic Affairs

(BMWA), "Monitoring Bericht" 2003, S.18

Figure 1: Partial Market Opening I: Electricity

There is some evidence for the empirical validity of these theoretical claims. In the electricity market, in Europe the opening of the market took place step by step, opening first the market for large industrial customers, then for intermediate customers, and finally for private households. These demands are independent. Indeed, prices decreased only in the segment opened to competition, not in the other markets. See figure 2 for a comparison of consumer prices of electricity in Germany versus industry prices. Although liberalization encompassed both markets, de facto competition developed only for industrial customers. These price have decreased, while the price in the monopoly market (consumer) has remained almost stable.

A similar reasoning holds for the telecommunications market in Germany. While long-distance and international calls were opened to competition in 1998 on the basis of call-by-call competition, local calls were excluded until 2003. A similar situation is found: the price in the noncompetitive sector was almost stable, the price of the competed segments-unsurprisingly-went down.

Although it is highly likely that the price will be closer to the RamseyBoiteux price in the market with competition, this is not at all certain. It could well be that the price was slightly above the Ramsey-Boiteux price before the opening of the market and is significantly below it afterwards. This could easily happen in the extreme case, in which, after the market is opened, competition takes the form of Bertrand competition, driving prices down to marginal cost.

When markets are opened to competition, competitors do not usually enter all markets at the same time; instead, entry occurs sequentially. Entrants typically choose to enter the most attractive markets first ("cream skimming"). This leads to an systematic deviation between Ramsey-Boiteux pricing and the prices resulting from profit maximization. Entry of competitors is biased towards markets with low price elasticity. Therefore, the residual demand an

where demand is elastic, i.e. $e_{j j}>1$. Thus, assuming a price decrease due to competition, the monopolists revenue $q_{j} p_{j}$ decreases with the introduction of competition. 


\section{Telecommunication Prices}

Germany

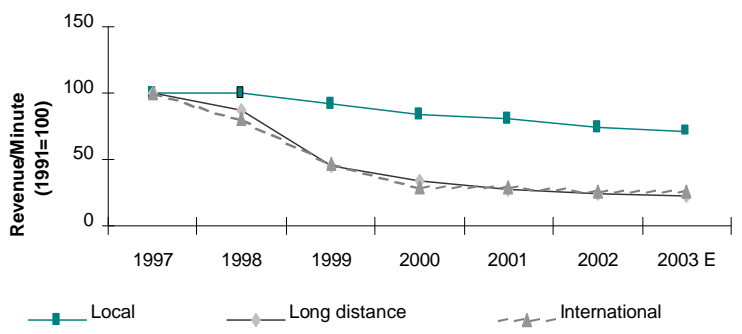

Source: RegTP, Annual Report 2002/03, Fig. 74 and 79 .

Figure 2: Partial Market Opening II: Telecommunications

incumbent faces tends to be inversely related to the market demand. This is illustrated in the following simple example. Assume $n$ markets with market demand $D_{i}\left(p_{i}\right)=p_{i}^{-\alpha_{i}}$. Assume that markets differ only with respect to their constant elasticity of demand $\alpha_{i}, i=1, \ldots, n$, where $\alpha_{i}>1$ and $\alpha_{i}<\alpha_{j}$ for $i<j{ }^{3}$ Markets are the same size, and marginal costs are identical for all markets, $c_{i}=c$ for all $i$, also the market entry cost $F_{i}$ are the same, $F_{i}=F$, for all $i$. Assume that initially all markets are served by an incumbent, who then sets his mark-up on marginal cost equal to $1 / \alpha_{i}$. Consider an entrant who can only enter one of the $n$ markets (e.g. because he is financially restricted). Competition in the market he selected is of the Cournot style. Straightforward computations show that he would then enter the market with the lowest price elasticity. ${ }^{4}$ Prices in this market then go down. If pre-entry prices were very close among markets (which would be the case if the elasticities are close), this change in the price of the market the entrant chose will suffice to change the order of prices.

Observation 7 Market entry tends to be biased towards markets with the lowest elasticities of demand. Price reduction due to competition will therefore occur

\footnotetext{
${ }^{3}$ With constant elasticities of demand, we need to assume elastic demand, $\alpha_{i}>1$, in order to ensure existence of a price equilibrium. For inelastic demand, $\alpha_{i}<1$, increasing prices would always increase profits.

${ }^{4}$ The Cournot profits of the two symetrical competitors in the market the entrants selects are:

$$
\pi_{i}=q_{1}\left(p_{i}-c\right)-F
$$

By symmetry, and assuming $F$ to be small enough such that entry is profitable, equilibrium quantity for each firm is given by:

$$
q_{i}^{*}=\frac{(2 c)^{-\alpha}}{2} .
$$

Cournot profits equal:

$$
\pi_{i}^{*}=2^{\frac{1-\alpha}{\alpha}} c^{1-\alpha}-c-F,
$$

which will be positive and therefore entry will be profitable for $F$ small enough. These profits are decreasing in the market's price elasticity $\alpha_{i}$. Thus, the entrant enters into market $i=1$.
} 
BT Market Shares (Volume)

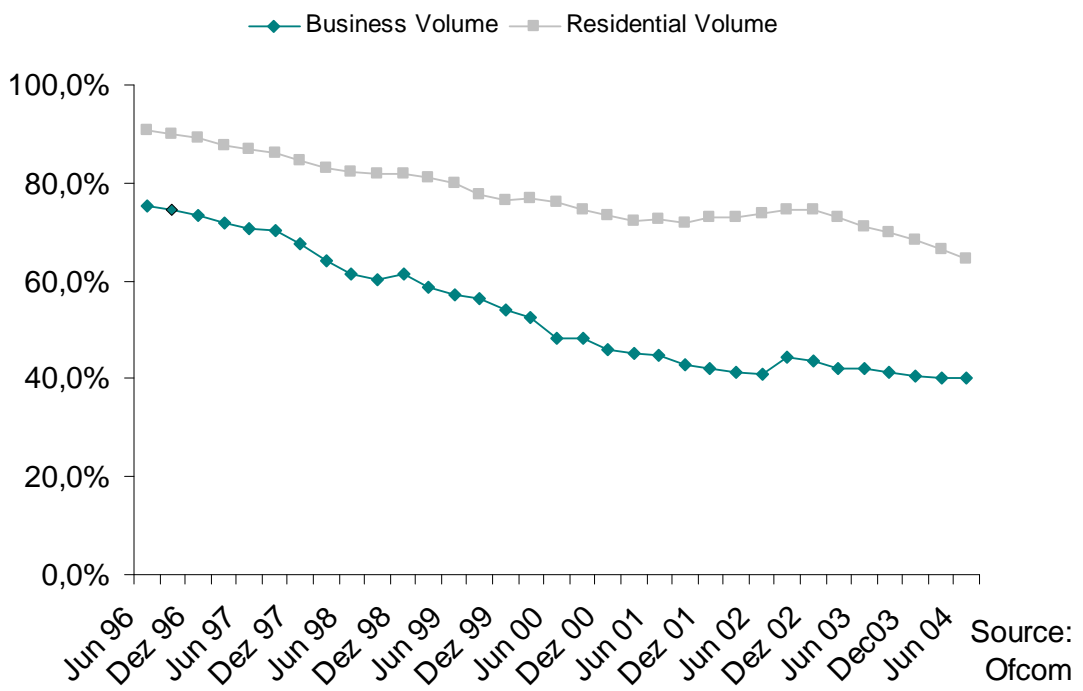

Figure 3: Stronger market entry in business segment

in those markets in which the Ramsey-Boiteux planner would set the highest mark-ups.

Some empirical evidence can be found when comparing business and residential customer markets for phone calls. The demand of business customers is usually regarded as less price elastic than residential demand, e.g. because they are bound to office hours and cannot postpone calls into less expensive off peak hours. (Taylor, 2002, 103-104) cites additional reasons for a lower elasticity for business customers. Competition for business customers is more intense than for residential customers, as reflected in the lower market share of BT, the British telecommunications incumbent, in the business segment, as can be seen from Figure 3.

Summary: When introducing competition, even the logic in which RamseyBoiteux and monopoly prices are set, is no longer the same, as the residual demand function (towards which profit maximization is orientated) and the market demand function (towards which the Ramsey-Boiteux planner is orientated) deviate.

\subsection{Introduction of competition in more than one market}

If there is competition in many or all markets, the prices of monopolists loose all resemblance with Ramsey-Boiteux pricing. This is just due to the fact that the relevant demand function for the monopolist, who we now refer to as the "dominant firm", is no longer the market demand. The dominant firm will set mark-ups according to the competitive pressure in each market. This is indeed the dominant firm's "business orientated" pricing and it will be ori- 
ented towards the residual demand's price elasticity, but it has little to do with Ramsey-Boiteux pricing. For instance, estimations for long distance telecommunications demand find a price elasticity for the residual demand function of individual long distance telecommunications operators up to 22.8 Hartman and Naqvi (1994)-while market demand is usually found to be price inelastic (i.e. price elasticity $<1$, see Taylor (2002)). Thus, little can be said when comparing the price systems of monopolists and Ramsey-Boiteux planners.

Observation 8 With competition in many markets, neither size, nor the structure, nor the "logic" of pricing is systematically similar between Ramsey-Boiteux and Monopoly pricing. Due to the divergence of market demand and residual demand, none of the similarities detected so far need to apply.

Nothing can be said generally about the welfare effects of monopoly pricing. In particular: reference to a lower elasticity of the residual demand of a (dominant) firm does not resemble the Ramsey-Boiteux argument and cannot be used to justify higher prices from a social welfare point of view.

For the sake of the argument assume two markets, $i=1,2$, both open to competition. Market 1 has a constant elasticity of demand of $\varepsilon_{1}$, market 2 has constant elasticity of $\varepsilon_{2}$. Demands are independent. Let $\varepsilon_{1}>\varepsilon_{2}$. Production is costly due to the same convex cost function $c\left(q_{i}\right)$. There is a common cost of production $F$ to be covered for the dominant firm. ${ }^{5}$ Ramsey-Boiteux pricing requires $p_{1}<p_{2}$. Now assume that market 2 is more competitive than market 1, in the extreme, assume perfect competition, yielding $p_{2}^{M}=c^{\prime}$. Market power in market 1 allows for $p_{1}^{M}>c^{\prime}$. Thus, the price structure is different in both cases due to the different competitive structure.

In the past, telecommunications operators have nevertheless used the argument of Ramsey-Boiteux pricing to justify higher prices in their less contested market segments. Prieger (1996) reports that some of the US regional telephony companies (like GTE, Pacific Bell) explicitly referred to an inverse elasticity rule when arguing for higher prices for (low competition) local access and lower prices for (high competition) long distance calls. T-Mobile UK argued in favor of mobile termination fees to be set at "Ramsey levels", with inverse elasticities with respect to the own residual demand in mind, see Ofcom (2003). Being precise whether one is referring to residual or market demand allows such misperception of Ramsey-Boiteux reasoning to be avoided.

Summary: With competition in many markets, differences in the elasticity of the residual demand and, therefore, price difference are likely to depend more on the competitive intensity than on the elasticity of the market demand.

\subsection{Intermediate Production and Access Pricing}

Since Ramsey-Boiteux pricing is about the set of least distortive mark-ups, it is inherently a welfare analysis. When investigating intermediate markets, any welfare analysis would be incomplete which does not account for effects on subsequent markets and, eventually, the final good market. The relationship between the upstream and downstream markets becomes important. We want

\footnotetext{
${ }^{5}$ We have a situation in mind where the dominant firm owns the network, while competitors have regulated access to the network. For market 1 (e.g. electricity for consumer) there are barriers to entry, while there are none for market 2 (e.g. electricity for industrial customers).
} 
to briefly discuss two different cases: First, a monopolist upstream, who is not active in the downstream market, with perfect competition in the downstream market; second, a typical access problem, with an upstream monopolist, who is also active in the downstream market, and where there is market power in the downstream market.

Consider the most simple case with an upstream multi-product monopolist who serves different intermediate final good markets. This could, for instance, be a "NetCo" of a municipal utility, operating different networks (electricity, natural gas, district heat, water, public transport) to realize operational synergies between the networks. Assume that the municipal utility is not active downstream (or provides non-discriminatory access to competing downstream retailers) and that the downstream retail market is competitive. In this environment, private profit maximization at each stage of the value chain leads to the same result that would occur if there were an integrated monopolist and no competition in the downstream market. ${ }^{6}$ The usual "inverse elasticity rules" apply, see e.g. (Laffont and Tirole, 2000, p.82). The outcome of monopolistic pricing and Ramsey-Boiteux pricing are characterized by observations 1 and 2 .

Observation 9 In a two stage value chain, with an upstream monopolist, who is not active in the downstream market, and with perfect competition downstream, downstream prices in the case of monopoly are similar to the RamseyBoiteux prices in the sense of observations 1 and 2.

A large amount of literature (Laffont and Tirole (1994), Armstrong, Doyle, and Vickers (1996), Laffont, Rey, and Tirole (1998a), Laffont, Rey, and Tirole $(1998 \mathrm{~b}))$ is devoted to the more complicated case of the optimal pricing of access to a network, where there is (i) a (natural) monopoly sector, and (ii) a potentially competitive sector, which requires some of the monopoly's output as an intermediate input. The standard application is telephony, where the local loop are regarded as a natural monopoly, while long-distance calls is regarded as potentially competitive. Any long distance service also requires local access to reach the final customer. At least for the case of linear pricing, even a RamseyBoiteux planner would set the access charge above the marginal cost of access. If the access charge were to equal the marginal cost, the network operator would have to recoup fixed cost solely from high retail prices. However, a high retail price benefits not only the network operator, but also the competitors in the final good market, which produces socially wasteful rents. At the same time, financing the fixed cost solely through the access charge is also not optimal, as the access charge determines the marginal cost of the firms in the second market, and with market power would lead to the double marginalization inefficiency (see e.g. (Laffont and Tirole, 2000, 105)).

Observation 10 In a typical access pricing problem à la Laffont, Rey, and Tirole (1998a), the Ramsey-Boiteux planner tends to set the access charge above the marginal cost of access.

Although the economic literature on efficient access pricing can provide many powerful results, it does so with little reference to the standard Ramsey-Boiteux

\footnotetext{
${ }^{6}$ The reason is that there is no additional mark-up on the intermediate product price due to perfect competition downstream. If there is market power in the retail market, the classical "double marginalization" problem arises and vertical integration could improve the welfare level.
} 
problem. The reason is that the interaction between intermediate and final product market has also to be taken into account. This makes any comparison between (i) a welfare optimizing set of prices à la Ramsey-Boiteux (ii) "monopoly pricing" and (iii) some form of "competitive pricing" more complicated. This complexity can not be covered by any simple reference to the "inverse elasticity rule".

Summary: The welfare analysis of intermediate product markets requires account be taken also of effects on subsequent markets. The standard RamseyBoiteux approach must be extended substantially to cover this case. A simple reference to results in the standard framework is usually not justified.

\subsection{Two Way Access and Termination Fees}

Finally, we discuss the relationship between Ramsey-Boiteux pricing and twoway access, in particular, termination fees in mobile telephony. Termination fees have to be paid by the network of the call-originating party to the company of the called party in order to deliver the call on the called party's network. ${ }^{7}$

The motivation for including this problem in the analysis here is only partially theoretical. As in the preceding subsection, the termination fee problem is too different from the standard Ramsey-Boiteux problem to make any simple reference to results from the Ramsey-Boiteux analysis meaningful. The practical regulatory debate has nevertheless made frequent reference to Ramsey-Boiteux pricing in the discussion of termination rates. Mobile network operators claimed that demand for termination is relatively inelastic compared to fixed monthly subscription fees or to call prices. Therefore charging relatively high termination fees would be in line with social welfare maximization, as operators have to finance the fixed and common cost of the mobile telecommunications network (Competition Commission, 2002, para 1.7, 2.435.). Similar arguments have been made in other countries, see e.g. Kruse (2003).

However, from an economic point of view, at least three issues arise when comparing the termination problem to the Ramsey-Boiteux problem.

We shall briefly discuss them in turn:

- Cost Situation: Only specific cost situations make an analysis à la RamseyBoiteux meaningful.

- Intermediate Production: Termination is an intermediate product-welfare analysis must account for the relation to the final product markets.

- Residual Demand: Termination issues arise in competitive settings in which the residual demand and the market demand are different.

Consider first the cost issue. If two or more networks overlap, as is usually the case with mobile networks, a Ramsey-Boiteux planner would first ask, whether more than one network is socially desirable. If this is the case, the RamseyBoiteux problem arises only if in this cost situation, setting price equal marginal cost gives rise to a deficit for some firms. Only very special cost situations result in such a constellation. Three properties are required. (i) The cost function of

\footnotetext{
${ }^{7}$ International roaming is an additional application area for this sort of problem. It differs from mobile termination, since mobile networks overlap, while international fixed networks do not overlap. A survey of termination can be found in Armstrong (2002).
} 
none of the potential suppliers is subadditive for the relevant region of the demand function. Otherwise, due to the natural monopoly character of the industry, least cost production requires production by this firm only. (ii) For $n$ firms to be socially optimal, the production vector $\left(x_{1}, \ldots, x_{n}\right)$, providing total supply $X=\sum_{n=1}^{n} x_{i}$, must be such that the cost for each firm is subadditive at $x_{i}$. Otherwise, the social planner could just split the production of the firm with non-subadditive cost and introduce a new firm (provided, that there is no scarcity of resources that prevent the social planner from replicating firms). (iii) Finally, as long as marginal costs are non-decreasing, the average cost for $x_{i}$ must exceed the marginal cost at $x_{i}$ for at least some firms. Otherwise, the Ramsey-Boiteux problem would not occur since firms could cover their fixed costs by setting price $=$ marginal cost. Few of the standard cost functions used in economic modelling fulfil these requirements. ${ }^{8}$ Nevertheless, such cost situations might occur in reality.

In (Baumol, Panzar, and Willig, 1988, p.337-338) another issue is highlighted which makes a situation less likely in which it is socially desirable to have more than a single firm while prices equal to marginal cost lead to losses. They show that for any given number of firms larger than one, industry cost are typically not minimized if one requires that each firm individually breaks even. This is due to the fact that the social planner needs to deviate from the cost minimizing situation in which the marginal costs are equal among firms. In the absence of subsidies, shifting quantities among firms is the only way to provide those firms (that would otherwise not break-even) with additional revenue and profits.

Observation 11 With overlapping networks the question arises whether a RamseyBoiteux planner would want to allow for more than one network. Only for specific cost functions the Ramsey-Boiteux problem (i.e. setting price equal to marginal cost results in a deficit) arises and at the same time the social planner would like to have more than one network.

We now turn to another problem, namely, that termination is an intermediate product. Assume that the cost situation is such that more than one firm is socially desirable and setting price equal to marginal cost does not cover the cost. Then the question of mark-ups arises. Mark-ups need to relate to final consumer demand, as they are chosen to minimize overall distortions, in particular in final consumption. Termination, however, is an intermediate product. An appropriate question is to what extent mark-ups on intermediate products translate into mark-ups for final products and to what extent this follows some inverse elasticity rule. For termination the relevant final service are voice calls, in particular, off-net calls, i.e. calls into other networks. Arguing that high termination rates are justified due to a low consumer demand elasticity requires a close correlation between termination rates and final prices. A brief look at aggregate data on call prices and termination rates in the UK casts some doubt on this assumption, see Figure 4.

\footnotetext{
${ }^{8}$ Examples for cost functions which do not fulfil the listed properties: (i) Constant marginal costs: If all firms have a cost function $C_{i}=F_{i}+c_{i} x_{i}$, then least cost production always requires production by a single firm. (ii) Symetrically increasing marginal cost: $C_{i}=F+c x_{i}^{\alpha}, \alpha>1$. Least cost production then has every firm producing at the same marginal cost and marginal cost $\geqq$ average cost (otherwise - abstracting from integer problems - the planer could reduce the number of firms, shift production to the remaining firms and reduce industry cost).
} 


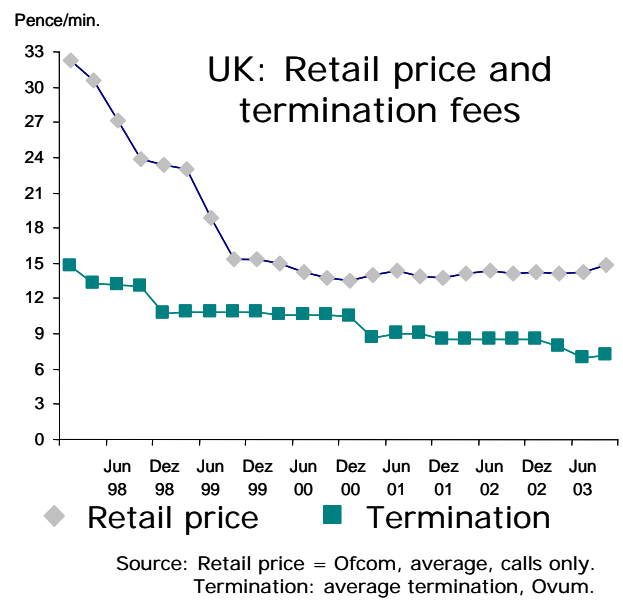

Figure 4: Termination Rates in the UK

Observation 12 Termination is an intermediate product. Its price has a limited impact on final service prices. Therefore, the Ramsey-Boiteux arguments can not be applied directly.

Finally, we turn to the issue of residual versus final market demand. To terminate a call on the network of an particular network operator, say $A$, the termination service of $A$ is the sole possibility. Thus, each operator is a monopolist with respect to termination in its own network. Although this monopoly power might be restricted to some extent (consumers might to some extent care for the cost imposed on calling parties within communities, like families or firms), a common ruling by regulatory authorities is that mobile operators enjoy "significant market power" with respect to termination fees. It is therefore not surprising that the demand for termination service is relatively inelastic. But this implies no positive welfare implications from high termination fees at all, as the difference in elasticities is more due to differences in the intensity of competition than to different demand elasticities for "access" (monthly subscription) and "off-net calls" (termination). Oftel, the UK regulator, employed precisely this logic in its arguments (Competition Commission, 2002, para. 2.437).

One test case for differences in demand elasticities, which could justify high termination rates, are on-net versus off-net calls. If higher termination rates were translated into higher off-net call prices (since only for off-net calls termination fees turn into cost, and if customer prices are cost based), and if demand for off-net calls were less price elastic than on-net calls, then high termination fees could be justified by Ramsey-Boiteux arguments. Vodafone, the largest operator in the UK, however denied that termination fees could be justified by differences in the price elasticities for on- and off-net calls (Competition Commission, 2002, para. 2.432.).

There is, nevertheless, a large economic literature on termination. The seminal papers by Laffont, Rey, and Tirole (1998a) and Laffont, Rey, and Tirole (1998b) discuss-among other things-questions of (i) overlapping versus nonoverlapping networks, (ii) uniform vs. two-part retail tariffs, (iii) price discrimi- 
nation between on-net and off-net calls, and (iv) reciprocal versus non-reciprocal termination charges. Further research by Gans and King (2001) and Behringer (2004) shows that the magnitude and even the sign of the mark-ups on termination costs crucially depend on the question of reciprocal or non-reciprocal access. The issue of whether only the calling party has to pay for the call (the standard rule in most countries) is analyzed in Hermalin and Katz (2004). None of this literature, however, is focused on the key question of a Ramsey-Boiteux planner: How can the fixed (network) cost be recovered? The model of Laffont, Rey, and Tirole (1998a) which has been used by many subsequent papers on the topic, does not consider any fixed cost of network build-up. ${ }^{9}$.

Summary: Ramsey-Boiteux pricing has little to contribute to the discussion of termination rates. It is unclear to which extent termination rates determine final customer prices and, if they do, whether the unregulated pricing structure has anything to do with the final customers' demand elasticities. And even if it does, all issues about absolute level of mark-ups discussed in section 4 apply.

\section{Conclusion}

The classical Ramsey-Boiteux approach is based on a static model of a single firm producing for a final consumer market. The Ramsey-Boiteux prices are similar to the prices of a profit maximizing monopolist in this framework only in the sense that at the implemented allocation (which is different in both cases) mark-ups on marginal cost will be higher for goods where demand is less price elastic. The size and order of the prices can, however, differ. Monopoly pricing is not in any general sense "more efficient" just because it is orientated on the price elasticity at the point realized on the demand function.

It is therefore not surprising that reference to Ramsey-Boiteux pricing offers even less insights for welfare analysis if one departs from the original assumptions of the Ramsey-Boiteux world. Allowing for competition in one or all markets-which is sensible for almost all regulated industries-causes market demand and residual demand of the "monopolist" to be different. The RamseyBoiteux planner is oriented at the price elasticity of the former, the monopolist of the price elasticity of the latter. Both typically deviate significantly from each other. Analyzing intermediate goods, network access, or termination also shows the limits of Ramsey-Boiteux reasoning: Economics can say a lot about these things-but not by referring to Ramsey-Boiteux concepts.

\section{References}

Armstrong, M. (2002): "The Theory of Access Pricing and Interconnection," in Handbook of Telecommunications Economics, ed. by S. K. M. Cave, Martin E., and I. Vogelsang, vol. 1, pp. 297-386, Amsterdam. Elsevier.

\footnotetext{
${ }^{9}$ Their fixed costs are subscriber acquisition costs, e.g. subsidization of a mobile handset. At one point they, however, they make reference to the standard Ramsey-Boiteux problem (Laffont and Tirole, 2000, p.196): A socially optimal termination fee would generally be below the marginal cost of termination in case of monopoly power in the retail market. This might not be the case in the presence of "common costs": The neccesary mark-up might increase the termination fee above marginal cost.
} 
Armstrong, M., C. Doyle, and J. Vickers (1996): "The Access Pricing Problem: A Synthesis," Journal of Industrial Economics, 44(2), 131-150.

Baumol, W. J., J. C. Panzar, and R. D. Willig (1988): Contestable Markets and the Theoriy of Industry Structure. Harcourt Brace Jovanovich, San Diego, Revised Edition.

Behringer, S. (2004): "Essays in Applied Microeconomic Theory," PhD Dissertation, University of Mannheim.

Boiteux, M. (1956): "Sur La Gestion Des Monopoles Publics Astreints A L'Equilibre Budgetaire," Econometrica, 24(1), 22-40.

Braeutigam, R. R. (1989): "Optimal Policies for Natural Monopolies," in Handbook of Industrial Organization, ed. by R. Schmalensee, and R. D. Willig, vol. 2, pp. 1289-1346, Amsterdam. Elsevier.

Competition Commission (2002): "Vodafone, O2, Orange and T-Mobile," Reports on references under section 13 of the Telecommunications Act 1984 on the charges made by Vodafone, O2, Orange and T-Mobile for terminating calls from fixed and mobile networks.

Gans, J. S., And S. P. King (2001): "Using 'bill and Keep' Interconnection Arrangements to Soften Network Competition," Economics Letters, 71, 413420 .

Hartman, R. S., and Z. F. Naqvi (1994): "Estimation of Household Preferences for Long Distance Telecommunications Carrier," Journal of Regulatory Economics, 6, 197-220.

Hermalin, B. E., and M. L. Katz (2004): "Sender or Receiver: Who Should Pay to Exchange an Electronic Message?," RAND Journal of Economics, 35(3), 423-448.

Kruse, J. (2003): "Regulierung der Terminierungsentgelte der Deutschen Mobilfunknetze?," Wirtschaftsdienst, (3), 1-6.

Laffont, J.-J., P. Rey, and J. Tirole (1998a): "Network Competition I: Overview and Nondisciminatory Pricing," RAND Journal of Economics, $29(1), 1-37$.

(1998b): "Network Competition II: Price Discrimination," RAND Journal of Economcis, 29(1), 38-56.

Laffont, J.-J., and J. Tirole (1994): "Access Pricing and Competition," European Economic Review, 38, 1673-1710.

MA.

(2000): Competition in Telecommunications. MIT PRess, Cambridge

Ofcom (2003): "Wholesale Mobile Voice Call Termination. Consultation 19/12/2003, Annex K.," Ramsey Price.

Prieger, J. E. (1996): "Ramsey Pricing and Competition: The Consequences of Myopic Regulation," Journal of Regulatory Economics, 10, 307-321. 
Ramsey, F. P. (1927): "A Contribution to the Theory of Taxation," Economic Journal, 37(145), 47-61.

TAYlor, L. D. (2002): "Customer Demand Analysis," in Handbook of Telecommunications Economics, ed. by S. K. M. Cave, Martin E., and I. Vogelsang, pp. 98-142, Amsterdam. Elsevier. 